\title{
МЕТАФОРИЧЕСКИЕ РЕПРЕЗЕНТАЦИИ ПОНЯТИЯ ВОДА В ПОЭЗИИ Ф.И. ТЮТЧЕВА
}

\author{
I.А. КАМСНСВА. МЕТАФОРИЧНІ РЕПРЕЗЕНТАЦІЇ ПОНЯТТЯ ВОДА В ПОЕЗІї \\ Ф.I. TЮТЧЕВA. \\ Стаття присвячена аналізу мовної репрезентації поняття вода в когнітивному
} аспекті. Світ природи і світ людини, які представлені в образах водної стихії, в поезї Ф.І. Тютчева об'єднуються за допомогою антропоморфної метафори. Актуальність роботи визначається важливістю дослідження мови поезії Ф.І. Тютчева, перш за все, семантики абстрактних понять, що в поетичному тексті набувають нових значень $і$ інтерпретації. Новизна роботи полягає у проведенні системного аналізу лексичних метафоричних засобів створення поетичного образу води та водної стихії в творчості Ф.І. Тютчева. У статті проаналізовані поетичні тексти Ф.І. Тютчева з метою виявлення в них метафор, основними значеннями яких є когнітивні структури різноманітних водних об'єктів. Семантичний аналіз метафор трунтувався на даних лексикографічних джерел. Метафоричне уявлення поняття вода в поезії Ф.І. Тютчева відображає основні особливості його творчості і бере участь у створенні поетичної картини світу. У статті описані основні мовні засоби, щяо репрезентують індивідуально-авторські метафори, пов'язані з водною стихією. Поняття вода в поезї Ф.І. Тютчева експлікується в метафорах: життя - море, життя - плавання, річка життя, життєвий струмінь, пучина морська, хвиля, потік; текти, лити, клекотіти, хльостати, ревти, литися, бити, цуміти, ремствувати, мчати, гриміти, виблискувати, струмувати, плисти, розливатися. На основі проведеного аналізу виявлено, що домінуючими $є$ дієслівні метафори, завдяки яким поет передає динаміку вічного руху, а також плавність, текучість, мінливість води, ї̈ здатність приймати різні стани. Метафоричні репрезентації поняття вода стають важливим елементом мовної картини світу Ф.І. Тютчева.

Ключові слова: метафора, когнітивна структура, поняття вода, мовні засоби.

\section{И.А. КАМЕНЕВА. МЕТАФОРИЧЕСКИЕ РЕПРЕЗЕНТАЦИИ ПОНЯТИЯ ВОДА В} ПОЭЗИИ Ф.И. ТЮТЧЕВА.

Статья посвящена анализу языковой репрезентации понятия вода в когнитивном аспекте. Мир природы и мир человека, представленные в образах водной стихии, в поэзии Ф.И. Тютчева объединяются при помощи антропоморфной метафоры. Актуальность статьи определяется важностью исследования языка поэзии Ф.И. Тютчева, прежде всего, семантики абстрактных понятий, которые в поэтическом тексте приобретают новые значения и интерпретации. Новизна работь заключается в проведении системного анализа метафорических средств создания поэтического образа воды и водной стихии в творчестве Ф.И. Тютчева. В статье проанализированы поэтические тексты Ф.И. Тютчева с иелью вылвления в них метафор, основными значениями которых являются когнитивные структуры различных водных объектов. Семантический анализ метафор основывался на данных лексикографических источников. Метафорическое представление понятия вода в поэзии Ф.И. Тютчева отражает основные особенности его творчества и участвует в создании поэтической картины мира. $B$ статье описаны основные языковые средства, репрезентируюшие индивидуально-авторские метафоры, связанные с водной стихией. Понятие вода в поэзии Ф.И. Тютчева эксплицируется в метафорах: жизнь - море, жизнь плавание, река жизни, жизненная струя, пучина морская, волна, поток; течь, лить, клокотать, хлестать, реветь, литься, бить, шуметь, роптать, нестись, греметь, сверкать, струиться, пльть, разливаться. На основе проведенного анализа вылявлено, что доминируюшими являются глагольные метафоры, благодаря которым поэт передает динамику вечного движения, также плавность, текучесть, изменчи-

() И.А. Каменева, 2019

https://doi.org/10.34142/2312-1572.2019.02.68.04 
вость воды, ее способность принимать различные состояния. Различные метафорические репрезентачии понятия вода становятся важным элементом языковой картины мира Ф.И. Тютчева.

Ключевые слова: метафора, когнитивная структура, понятие вода, языковые средства.

\section{I.A. KAMIENIEVA. METAPHORIC REPRESENTATION OF THE CONCEPT WATER IN} THE POETRY OF F.I. TYUTCHEV.

This article is devoted to the analysis of the language representation of the concept water in the cognitive aspect. The world of nature and the world of man in the poetry of F.I. Tyutchev are combined with the help of an anthropomorphic metaphor. The relevance of the article is determined by the importance of the language study of F.I. Tyutchev poetry and above all the semantics of abstract concepts, which in the poetic text acquire new meanings and interpretations. The novelty of the work consists in carrying out a system analysis of the metaphorical means of creating a poetic image of water and water elements in F.I. Tyutchev poetry. The article analyzes the poetic texts in order to identify metaphors in them, which main values are cognitive structures of various water objects. Semantic analysis of metaphors is based on data from lexicographic sources. Metaphorical representation of the concept water in F.I. Tyutchev poetry reflects the main features of his work and is involved in creating poetic picture of the world. The article describes the main language expressions that represent the individual author's metaphors associated with the water element. On the base of the analysis, it has been revealed that verb metaphors are dominant, thanks to which the poet gives the dynamics of perpetual motion, as well as smoothness, fluidity, water variability, the ability to accept various states. Various metaphorical representations of the water concept become an important element of the linguistic picture of F.I. Tyutchev's world.

Key words: metaphor, cognitive structure, concept water, language expressions.

В основе мира поэзии Ф.И. Тютчева лежит мифологический мир стихий. Многие исследователи, среди которых В.Н. Касаткина, Б.М. Козырев, Л.А. Озеров, отмечают особую роль водной стихии [2; 3; 4]. Ее объекты воплощены в художественных образах, которые помогают понять особенности личности самого поэта, его мировосприятия и мировидения.

Цель данной статьи - исследование языковых особенностей метафорического переосмысления понятия вода в поэзии Ф.И. Тютчева.

Актуальность темы обусловлена тем, что она отвечает современным тенденциям лингвистики, ее стремлению к рассмотрению языка с антропоцентрических и когнитивных позиций, конкретным проявлением чего является описание метафорических образов понятия вода на примере поэзии Ф.И. Тютчева

В поэтической системе Ф.И. Тютчева большое значение уделяется символике воды как источника жизни, которая имеет место практически во всех мифологиях и поэтических традициях. Самыми распространенными являются метафоры, связанные с водной стихией: жизнь - море, жизнь - плавание, река жизни. Жизнь человека у Ф.И. Тютчева метафорически соотносится с водной стихией, поскольку вода ассоциативно связана с источником жизни. В античные времена в латинском языке появилось выражение aqua vivam, что буквально переводится, как “живая вода”.

Основными типичными смыслами, характерными для образа воды, являются движение, текучесть, изменчивость, которые передаются при помощи глаголов.

Способность воды к движению связывается в тютчевской языковой картине мира со временем жизни человека. Так, например, в стихотворении «Поток сгустился и тускнеет...»:

Так и в груди осиротелой,

Убитой хладом бытия,

Не льется юности веселой,

Не блещет резвая струя, -

Но подо льдистою корой

Еще есть жизнь, еще есть ропот -

И внятно сльишится порой

Ключа таинственного шепот!

В основе композиции наблюдается сопоставление природного и человеческого мира. Явление природы - вечную жизнь ключа - поэт сравнивает с юностью, которая живет под 
хладом бытия. Наиболее полное восприятие жизни у человека в юности, когда хочется веселиться, резвиться. Это пора беззаботности, когда жизнь должна бить ключом. Но, несмотря на то, что на склоне лет не льется и не блещет струя, ничто не может убить душу человека: ни время, ни утраты. Ф.И. Тютчев противопоставляет юность (резвая струя) и старость (ключа таинственного шепот): динамика движения жизни изменяется, уже не настолько интенсивна, как в юности, но не прекращается, а приглушается, словно шепчет.

Вода в метафорическом плане у Ф.И. Тютчева служит основанием жизни, ее двигателем:

Такою страшною ценой,

Что память эта и поныне -

И вашей лучшею святыней,

И вашей жизненной струей

(«Чехам от московских славян»).

Текучесть как одно из основных свойств воды, света, запаха семантически сближает такие глаголы, как литься, струиться, течь.

У глагола течь метафорические значения возникают в связи с переносом действий с конкретных предметов на абстрактные, при этом реализуется свойственная глаголам движения пространственно-временная семантика:

Та жизнь, увьг! что в нас тогда текла,

Та злая жизнь, с ее мятежным жаром,

Через порог заветный перешла?

(«Итальянская villa»).

В данном стихотворении метафорическое значение глагольной лексемы поддерживает контекст движения жизни.

Основанием жизни у Ф.И. Тютчева также служит и волна как часть водной стихии. Переносное метафорическое значение производно от прямого, номинативного: «водяной вал, образуемый колебательным движением водной поверхности (моря, реки)» [7]. Внезапность вздымающихся волн роднит море с жизнью, полной взлетов и падений.

Образ морской волны, как метафорическое переосмысление жизни человека, у поэта представлен двояко: как бурная, мятежная стихия, пучина морская, находящаяся в постоянном движении (бъет, шумят, ропщут) и как спокойная, мелодичная (баюкает):

По-прежнему шумят и ропщут волны...

(«Вопросы (Из Гейне)»);

Беспрерывно вал морской

С ревом, свистом, визгом, воем

Бвет в утес береговой...

(«Море и утес»).

Передача семантики глагола бъет усиливается субстантивами в творительном падеже с ревом, свистом.

При интенсивном движении, когда волны находятся в боренье, возникают антропоморфные звуковые образы: ропщут волны («Вопросы»), волны лезут с воем («Море и утес»).

У Ф.И. Тютчева движение волны представлено весьма разнообразно по своей интенсивности. Волна выступает как одухотворенная стихия, она полна чудной жизни, и поэтому движение морских волн зачастую связывается с миром человека. Иногда это спокойное движение:

Сны играют на просторе

Под магической луной

И баюкает их море

Тихоструйною волной...

(«По равнине вод лазурной...»).

Метафорическая проекция жизнь - опасная стихия актуализируется поэтом посредством образа бушующего моря, волны, выдвигаются на первый план такие характерные признаки жизни, как опасность, непредсказуемость, сложность преодоления жизненных трудностей, житейских невзгод.

Находясь в постоянной динамике, волна реализует особый вид кругового движения, что является у Ф.И. Тютчева своеобразным знаком активности жизни: 
И бунтует, и клокочет,

Хлещет, свищет и ревет,

И до звезд допрыгнуть хочет,

До незыблемых высот...

(«Море и утес»),

Зыбь ты великая, зыбь ты морская,

Чей это праздник так празднуешь ты?

Волны несутся, гремя и сверкая,

Чуткие звёзды глядят с высотьл

(«Как хорошо ты, о море ночное...»).

В первом отрывке с помощью глагольного ряда с оглушительными гласными бунтует, клокочет, хлещет, свищет, рвет нагнетается действие, как бы собирая силы воды перед прыжком. Данное сочетание глаголов градуирует движение до его высшей точки. Волна хочет допрыгнуть, но добраться, достигнуть незыблемых высот так же, как человек, не может. Здесь представлена ярко выраженная антропоморфная метафора. Все стихотворение представляет собой развернутую метафору отношений между судьбой и человеком. Взбунтовавшееся море суть бунтарской природы человека, которую поэт мастерски воссоздал благодаря использованию глагольной лексики.

Во втором отрывке сема быстрого движения подтверждается глаголом несутся. Абсолютность движения усилена глаголом празднуешь, а также глагольными формами гремя, сверкая, которые указывают на динамику процесса нарастания волн. Движение происходит не только по горизонтали, но и по вертикали, где верх сопряжен с низом. Небо своей прозрачностью и призрачностью (тусклое сиянье, чуткие звезды) кажется противопоставленным морю, но поэт и сближает их, создавая неразделимый комплекс, организующий пространство: море - низ, небо - верх.

Переносное значение глагольных лексем, обозначающих способы движения воды, основывается на сходстве в способе представления человеческих действий.

Метафорическое значение у глаголов наливать и пролиться связано с переносом из сферы психологического мира на предмет: «Радость грозды наливает...» («Песнь радости»), «И радость в сердие пролилась...» («Весна»).

В контекстах анализируемой поэзии часто наблюдается сближение глаголов литься и струиться по семантике. Глагол струиться у Ф.И. Тютчева в большинстве случаев обозначает свет и звук. Антропоморфные или природные метафоры, обусловленные свойствами воды, составляют большинство употреблений глагола:

И груди ровное дыханье

Струилось в воздухе слышней

(«Вчера, в мечтах обвороженных...»),

И стройный мусикийский шорох

Струится в зыбких камышиах

(«Певучесть есть в морских волнах...»),

Знамена гордо развевались,

Струились молнией штыкии...

(«Неман»),

Тихо в озере струится

Отблеск кровель золотых...

(«Тихо в озере струится...»),

Лишь по задумчивой Неве

Струится лунное сиянье

(«Опять стою я над Невой...»).

Высокая частотность использования глагола струиться свидетельствует о том, что поэт употребляет его намеренно и наделяет особыми коннотациями, отражающими интенсивность движения. Почти всегда данный глагол расположен в начале строки, а принцип восходящей звучности первых трех консонантов в слове усиливает эффект движения и непрерывность действия. Здесь вода составляет основу и воздушной стихии.

В стихотворениях, в которых присутствует тема моря, океана, появляется образ окутанного таинственностью звездного неба, который является ключевым, объединяющим 
пространство верха и низа: верх - горящзая слава звездная, а низ - пылающая бездна. Таким образом, мы видим, что пьлающая бездна - это звезды, отраженные в воде:

Небесный свод, горящий славой звездной,

Таинственно глядит из глубины, -

И мы плывем, пылающею бездной

Со всех сторон окружены

(«Сны»).

Слова море, океан сопровождаются глаголами объемлет, бъет, pacmem, уносит, которые играют важную роль в создании художественного пространства. Благодаря лексическому окружению океан можно соотнести с безграничностью (стихия, неизмеримость темных волн).

Сближение водной и воздушной стихии характерно для движущейся воды, семантика которых располагает возможностями для метафоризации.

Употребление глагола пльть в прямом значении связывается с передвижением по воздушной стихии:

Светло и тихо облака

Пльвут надо мною!..

(«Весеннее успокоение»),

Над виноградными холмами

Пльвут златые облака

(«Над виноградными холмами...»).

Семантика метафорического перемещения глагола пльть передает плавность, неторопливость движения. Поэт двойственно трактует водную стихию: путешествие по воде переносится в пространство пьлающей бездны,, где образ лодки как символа жизни поддерживается сочетанием звуков пл-.

Движение сверху вниз поэт передает при помощи глагола лить:

Солние знает ли о том,

Что оно-то жизнь в природу

Льет в сиянье золотом...

(«Н.С. Акинфьевой»),

В обители отичов все льет отраду нам!

(«Послание Горация к Меценату...»).

Повторы глаголов придают динамику движения. Во всех этих употреблениях глагол лить вбирает «в себя неопределенно-долгое течение времени... с особенной полнотой и силой» [7, с. 282-283].

Глагол разлиться в тютчевских словоупотреблениях реализует пространственновременную семантику:

...Сажусь задумчивый в тени древес густой,

И разливаются передо мной

Разнообразные вечерние картинь!

(«Одиночество»),

Так разливайся, жизни сладость...

(Весна»).

Прием аллитерации зл/зл (разливайся, разливаются) и сл (сладость), особенно использование плавного консонанта $л$, акцентирует внимание на том, что вода разливается постепенно, и конец этого процесса замедляется: уменьшение интенсивности звучания переносится на интенсивность движения.

Следует отметить, что глагол разливаться определяет следующие семантические сферы для метафорических переносов: «физический процесс - движение»; «физический процесс эмоциональное состояние» [5, с. 219]. Семантика перемещения переносится на духовную и физическую сферу человека для создания изобразительной метафоры.

В поэзии Ф.И. Тютчева встречается производная глагола разливаться: разлитый. Это причастие-прилагательное обладает не только пространственной, но и временной семантикой, на что указывают контекст:

Tbl, разлитая как море,

Дивно-пышная волна,

Приюти в своем просторе 
Тайну скромного челна!

(«На Неве»),

Их жизнь, как океан безбрежный,

Вся в настоящем разлита

(«Весна»).

Время - одно из онтологических понятий, над которыми поэт размышлял на протяжении всего творчества. Водная стихия - это основание метафоры, передающей движение жизни. Поэтом создается сложная метафора поток, где собственно номинация впитывает в себя время.

Образ стремительно уходящего времени реализуется Ф.И. Тютчевым при помощи метафорического употребления слова поток:

От желчи горького сознанья,

Что нас поток уж не несет

И что другие есть призванья,

Другие вызваны вперед

(«Когда дряхлеющие силы...»).

Стихотворение проникнуто идеей неодолимости движения вперёд, сознания того, что неудержимо несущийся жизненный поток невозможно остановить, так же, как невозможно повернуть вспять «всесильную волну»:

А тыл пльвви, пльвии, ладья,

Куда несет поток!

(«Приветствие духа).

Образы, связанные с водной стихией, являются компонентами более широкого или компаративного образа, а реализованные в контексте прямые значения слов с семантикой воды переосмысливаются в образно-символические: поток жизни впадает в море вечности, жизнь, как океан безбрежный.

Проводя параллель между жизнью и океаном, морем, поэт указывает на их масштабность, а река связывается с постоянным течением, необратимостью. Эти ассоциации актуализируются в метафорах, основными значениями которых являются когнитивные структуры названых водных объектов.

Основная особенность тютчевской поэзии проявляется в том, что, употребляя номинации важнейших понятий водной стихии в прямом значении, он создает высокопоэтические, запоминающиеся, оригинальные метафорические образы за счет их контекстуального окружения.

Метафорические репрезентации понятия вода в творчестве Ф.И. Тютчева отражают различные признаки данного слова. Наряду с такими признаками, как движение, безграничность, текучесть, изменчивость, встречаются и индивидуально-авторские. К таким можно отнести стихийность, способность принимать разные состояния. В формировании метафорических переносов участвуют различные репрезентации понятия вода: море, струя, поток, что подчеркивает разнообразие характеристики воды. Благодаря использованию глагольной лексики показан не только динамизм водной стихии (бунтует, клокочет, хлещет), но и ее плавность движения (пльть, струиться, разливаться). Метафорическое представление номинаций движущейся воды становится важным элементом языковой картины мира поэта.

\section{ЛИТЕРАТУРА}

1. Голованевский А.Л. Семантика движения в языке поэзии Тютчева. Вестник Брянского государственного университета. №2. 2012. Брянск: РИО БГУ. С. 258-363.

2. Касаткина В.Н. Поэтическое мировоззрение Ф.И. Тютчева. Саратов. 1969. 256 с.

3. Козырев М.Б. Письма о Тютчеве. В 2-х книгах. М.: Наука. 1988. Кн. 1. 590 с. С. 70 131.

4. Озеров Л.А. Поэзия Тютчева. М. 1975. 112 с.

5. Тодосиенко 3.В. К проблеме семантической классификации глагольной системы в разноструктурных языках. Вестник Челябинского государственного педагогического университета. 2013. №6. С. 209-221.

6. Тютчев Ф.И. Полное собрание стихотворений. Л.: Советский писатель. 1987. 448 с. 
7. Ушаков Д.Н. Толковый словарь русского языка: в 4 т. М. 1935-1940. URL: https://gufo.me/dict/ushakov/\%D0\%B2\%D0\%BE\%D0\%BB\%D0\%BD\%D0\%B0 (Дата обращения 2 февраля 2019 г.)

8. Чичерин А.В. Стиль лирики Тютчева. Контекст 1974. Литературно-теоретические исследования. М.: Наука. 1975. С. 275-294.

(Статья поступила в редакцию 18 марта 2019 г.) 